\title{
Achieving structural anisotropy of liquid crystalline epoxy by manipulation with crosslinking parameters
}

\author{
M. Kisiel ${ }^{*}$, B. Mossety-Leszczak ${ }^{1}$, B. Strachota ${ }^{2}$, A. Strachota ${ }^{2}$ \\ ${ }^{1}$ Department of Industrial and Materials Chemistry, Rzeszów University of Technology, Al. Powstańców Warszawy 6 , \\ 35-959 Rzeszów, Poland \\ ${ }^{2}$ Institute of Macromolecular Chemistry v.v.i., Academy of Sciences of the Czech Republic, Heyrovskeho nam. 2 , \\ CZ-162 00 Praha, Czech Republic
}

Received 29 June 2020; accepted in revised form 27 August 2020

\begin{abstract}
The article presents a detailed study of the curing process of liquid crystalline epoxy resin focused on selecting optimal crosslinking conditions allowing to achieve a highly anisotropic product. By the manipulation of time, temperature, and applied magnetic induction during the chemical reaction, leading to the formation of neat epoxy and carbon-epoxy composite, the desired conclusions were developed. During X-ray analysis, it was established that the most anisotropic network is created when the following parameters are chosen: low curing temperature, short time of curing, and high magnetic induction. These conditions, however, do not allow to synthesize fully cured products, so the two-stage process was proposed, which slightly deteriorates the level of anisotropy, giving maximum conversion in return. The level of order is described with a dependent on the intensity of peaks present on the X-ray scattering plots parameter called the orientation function OF. The introduction of a graphite-like nanofiller generally slightly decreases the anisotropy of the polymer network. The main finding of this article is the optimized process of curing, allowing to obtain highly anisotropic material. This optimization shows tendencies between material ordering and curing properties, so it can be useful in future studies allowing to reach optimal conditions a lot faster.
\end{abstract}

Keywords: polymer composites, smart polymers, thermosetting resins, material testing, nanocomposites

\section{Introduction}

Liquid crystalline epoxy resins are state-of-the-art materials that combine properties of conventional epoxies and liquid crystals. Both classes of materials with seemingly separated areas of application can become interesting and valuable for scientists and industry.

Epoxy resins are known for many decades, and their popularity is caused by the versatility of possible applications thanks to their unique properties. The proof of demand on this type of material is in the number of scientific papers written on this topic collected in comprehensive review articles from both the last years and more distant past [1-3]. This type of thermosetting material offers good mechanical and thermal properties, the possibility of use as coatings, insulators, and matrices for top-class composites, what is described in detail in the cited literature [4-6].

Liquid crystals, on the other hand, offer different, more sophisticated properties like the capability of ordering on the molecular level using an external force field (electric or magnetic) [7-9]. Creating a combined material - the liquid crystalline epoxy resin (LCER) allows to synthesize anisotropic polymer network with new properties, and this achievement was also thoroughly studied in the last years [10]. Some interesting aspects of LCER are superior thermal and mechanical properties [11], the anisotropy 
of electrical properties [12], and the use of this type of resins as matrices of highly ordered nanocomposites [13-16]. Liquid crystalline polymers can also be responsive to environmental stimulus, like light [17, 18], electric field [19], or temperature [20] and present shape memory [21], what makes them very interesting in the field of biomaterials and medicine.

Many properties mentioned above are possible after inducing structural anisotropy of cured polymer network, so it is important to optimize the process of achieving this molecular order. This paper describes a thorough investigation concerning this matter by stepwise manipulation of curing parameters and evaluation of the extent of ordering using $2 \mathrm{D}$ X-ray scattering. The conclusions can be easily drawn from a visual comparison of diffractograms, but the mathematical procedure developed in earlier studies [22] is employed to ensure the correctness of deduction. The main aim of this paper is to optimize the cure to obtain the most anisotropic material possible with maximum epoxy group conversion. Based on findings presented in this article, it should be possible to drastically speed-up the process of determination of optimal curing conditions for new, as yet undescribed systems.

\section{Experimental}

\subsection{Materials}

The liquid crystalline epoxy resin bis[4-(10,11epoxyundecanoyloxy)benzoate] $p$-phenylene (LCER), used in this study, was synthesized in our laboratory according to the procedure described in detail in the literature [23]. The crosslinking agents 4,4'-diaminodiphenylmethane (4,4'-DDM), 3,3'-diaminodiphenylmethane $\left(3,3^{\prime}\right.$-DDM) and acetone were purchased from Sigma Aldrich, Missouri, USA (products catalog numbers: 32950 - 4,4'-DDM; 378267 -3,3'-DDM and acetone -8.22251 ). The chemical structures and thermal characteristics of LCER, 4,4'-DDM, and 3,3'-DDM were shown in Figure 1.

As a carbon filler, a thermally modified anthracite described as SV2000 was used. Svierdlovski anthracite from Donbas, Ukraine was selected as the raw carbon material due to its high carbon content (95 wt\%) and high structural homogeneity. It was treated according to the procedure described by Pusz et al. [24].

\subsection{Method}

\subsubsection{Preparation of thermosetting compositions}

To prepare epoxy/carbon composites LCER/(3,3'- or 4,4'-)DDM/SV2000, $2 \mathrm{~g}$ of the liquid crystalline epoxy resin LCER (1.76 g/2.46 mmol), a stoichiometric amount of proper DDM isomer $(0.244 \mathrm{~g} / 1.23 \mathrm{mmol})$ and optionally $0,1 \mathrm{~g}$ of SV2000 filler (what gives $4.7 \mathrm{wt} \%$ of total mass and $5 \mathrm{wt} \%$ of the mass of the resin and the hardener) were first put together with ca. $20 \mathrm{ml}$ of acetone, shaken for 2 hours and homogenized by sonication for 1 hour at room temperature. The solvent was then evaporated under vacuum at room temperature, and the so-prepared mixture was stored at about $10^{\circ} \mathrm{C}$ before curing. Finally, $100 \mathrm{mg}$ samples of every mixture: LCER/(3,3'- or 4,4'-)DDM and LCER/(3,3'- or 4,4'-)DDM/SV2000, were placed in Teflon molds $(5 \mathrm{~mm} \times 4 \mathrm{~mm} \times 8.5 \mathrm{~mm})$ and cured under stepwise-changing parameters in sets of 40 samples for each composition. The curing temperatures are $155,160,165,170$, and $175^{\circ} \mathrm{C}$, and the curing time is $10,30,90$, and 180 minutes. This set gives 20 samples, and the whole procedure is conducted for two values of magnetic induction: 0.1 and 1.2 T. The samples were cured in a magnetic field using RTM-1 device from REMEL S.C. Nowy Targ, Poland equipped with neodymium magnets providing the homogeneous magnetic field with magnetic induction up to $1.2 \mathrm{~T}$.
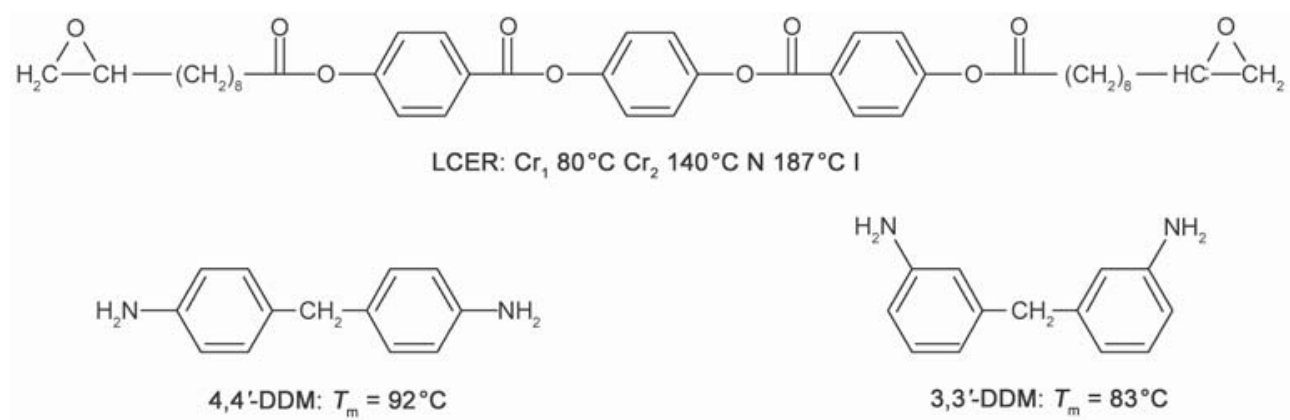

Figure 1. Chemical structures and thermal characteristics of LCER and curing agents. 


\subsubsection{Differential scanning calorimetry (DSC) analysis}

The DSC analyses were performed on a Mettler Toledo DSC $822^{\mathrm{e}}$ instrument with STARe System software. The thermal curves were recorded at the heating rate of $10 \mathrm{~K} / \mathrm{min}$, under nitrogen with a flow of $60 \mathrm{ml} / \mathrm{min}$. Calibration standards were indium and zinc supplied by Mettler Toledo.

TOPEM $^{\circledR}$ analyses were performed with a heating rate $2{ }^{\circ} \mathrm{C} /$ min with temperature amplitude $0,5^{\circ} \mathrm{C}$ and frequency of $1 \mathrm{~Hz}$.

\subsubsection{Wide/small angle $X$-ray scattering (WAXS/SAXS) analysis}

$\mathrm{X}$-ray diffraction measurements were performed using a NanoStar-U diffractometer (Bruker) with a two-dimensional detector in transmission geometry. $\mathrm{X}$-rays of the wavelength $\lambda=1.54 \AA$ were produced by a radiation copper lamp, powered by $600 \mu \mathrm{A}$ at $50 \mathrm{kV}$. The diffractometer was equipped with two Göbel mirrors for monochromatization and aligning parallel the beam of $500 \mu \mathrm{m}$ diameter. The measurements were carried out at room temperature $\left(22 \pm 2^{\circ} \mathrm{C}\right)$. The range of scattering angle was $0^{\circ}$ to $28^{\circ}$. Scattering angles and intensity were determined with the use of Bruker AXS DIFFRAC $>$ SAXS V.1.0 and Bruker AXS SAXS: Small Angle X-ray Scattering System V4.1.46 software.

Orientation function [22] was described with the Equation (1):

$O F=\frac{180-F W H M}{180} \cdot \frac{I_{\max }-I_{\min }}{I_{\max }}$

where $O F$ - orientation function (the level of molecular order), $F W H M$ - full width at half maximum, $I_{\max } / I_{\min }-$ maximum $/$ minimum peak intensity.

\subsubsection{Dynamic mechanical analysis (DMA)}

The dynamic mechanical analysis was performed using the ARES G2 apparatus from TA Instruments, in the shear mode at a constant frequency of $1 \mathrm{~Hz}$, at a heating rate of $3^{\circ} \mathrm{C} / \mathrm{min}$, registering the shear modulus $G^{\prime}$ and the mechanical loss coefficient $\tan \delta$. The temperature range in which the analyzes were carried out was $30-150^{\circ} \mathrm{C}$, and the samples had a cuboidal shape with dimensions of $1 \times 5 \times 5 \mathrm{~mm}$.

\subsubsection{Polarized optical microscope (POM) observations}

Photographs of observations in an optical polarizing microscope were taken using a Nikon Eclipse LV100POL microscope with a magnification of 70×. The observations were carried out by heating the test sample at the rate of $5{ }^{\circ} \mathrm{C} / \mathrm{min}$, thanks to the use of a Linkam THMS 600 heating bridge and a Linkam TMS 94 driver. Pictures were taken automatically every $2{ }^{\circ} \mathrm{C}$. Samples were prepared by depositing drops of a suspension of the test compositions in acetone on a microscope slide and allowed the solvent to evaporate.

\subsection{6, Scanning electron microscopy (SEM) observations}

Photos of the fractures of the samples were taken using the FEI Quanta 250 FEG scanning electron microscope, equipped with secondary electron detectors (ETD and LFD). The microscopic observations were carried out in low and high vacuum modes with a variable voltage in the range of $5.0-20.0 \mathrm{kV}$. Before the observations, the samples were covered with a layer of gold about $5 \mathrm{~nm}$ thick.

\section{Results and discussion}

\subsection{Determination of curing temperature range and preparing rules for stepwise- changing curing parameters}

Figure 2 is a representation of the DSC curves of analyzed systems. Based on this analysis and previous studies $[11,25]$ temperature range of $155-175^{\circ} \mathrm{C}$ was determined as potentially optimal as LCER needs to be both fully cured and 'have time' to become molecularly arranged. The other peaks on the thermal curve are the polymorphic transition of the LCER occurring at ca. $80^{\circ} \mathrm{C}$ which is partially $\left(4,4^{\prime}-\mathrm{DDM}\right)$ or fully (3,3'-DDM) overlapping with the melting of the curing agents and the transition from crystal to the liquid crystal at about $130^{\circ} \mathrm{C}$. Differences between pure components of the mixture and their behaviour in the curing system come from their mutual interactions. For whole studies, the samples were prepared with the parameters described in the Experimental section. They were designed for finding dependencies between the level of order and curing conditions. 
^exo

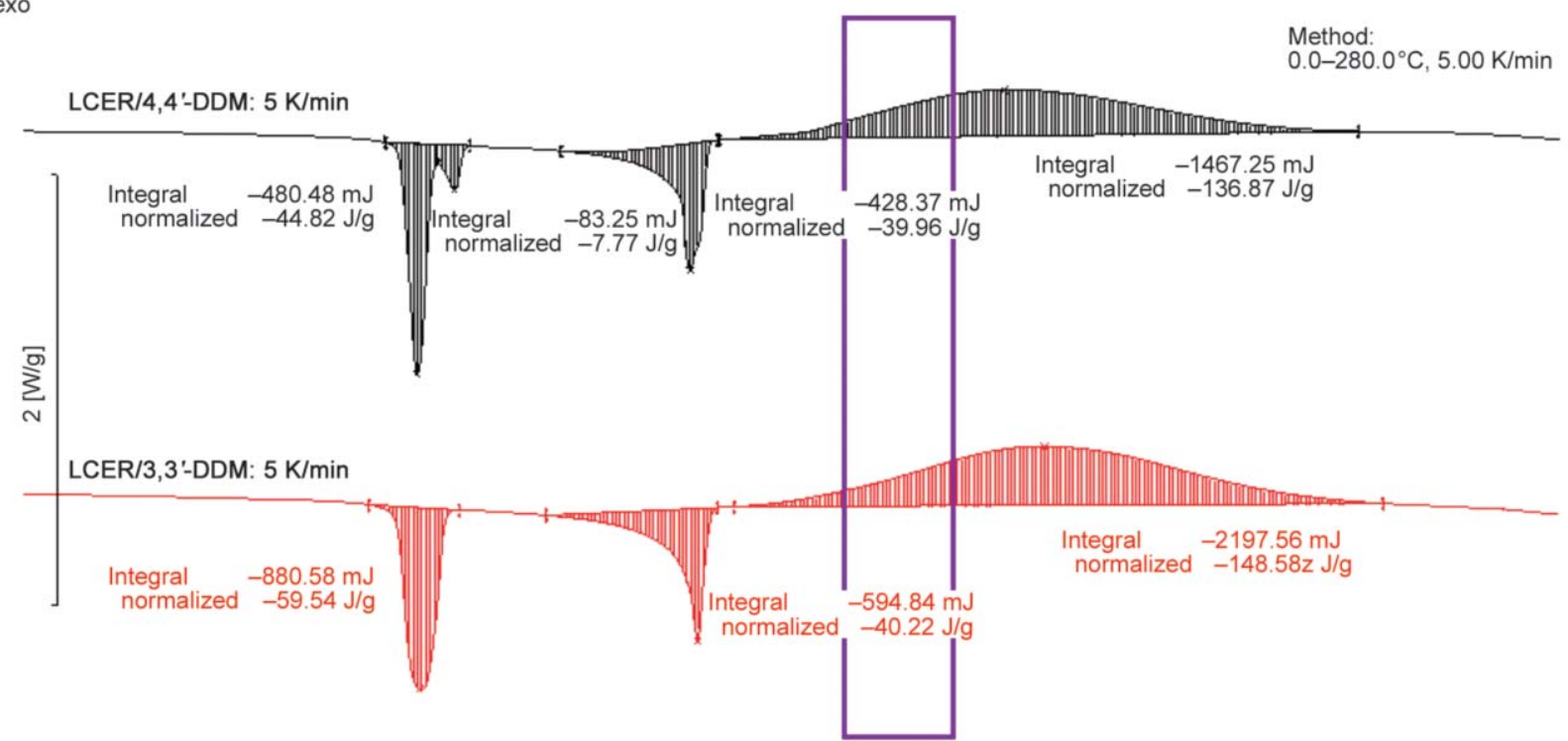

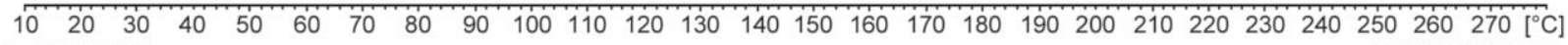
Lab: METTLER

Figure 2. DSC curves of analyzed thermosetting systems.

The control sample was prepared with no magnetic induction applied and cured at $175^{\circ} \mathrm{C}$ for 3 hours. This sample turned out to be fully isotropic with absolutely no order, as expected. This finding was supported with POM observations, where possible to order LC phase is clearly present only in lower values of curing temperature range (for systems with both curing agents). Figure 3 presents those micrographs, where colorful images characteristic for liquid crystal under POM microscope disappear along with the rise of temperature. Unfortunately, those images are captured without the presence of the magnetic field because of the interference of a strong magnetic field with electronic devices.

\subsection{Procedures for evaluation of the level of order and the degree of curing}

WAXS analysis was performed to determine the anisotropic properties of investigated samples. Three values of scattering angles were used in calculations

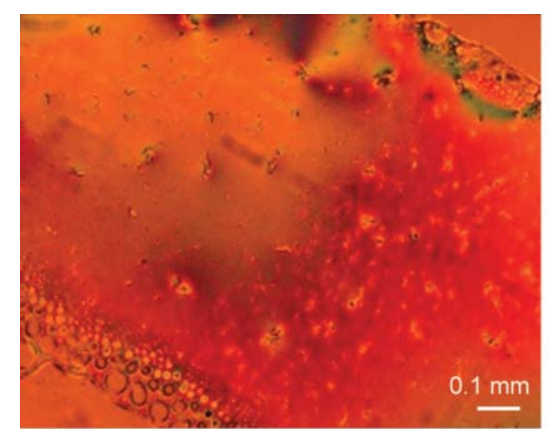

a)

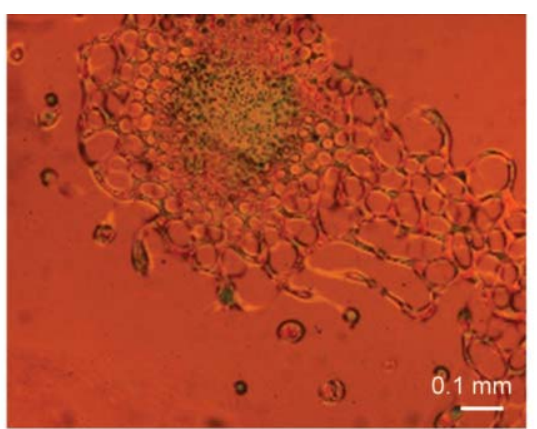

b)

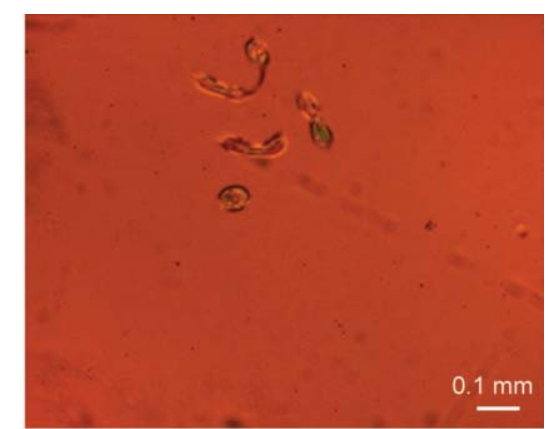

c)

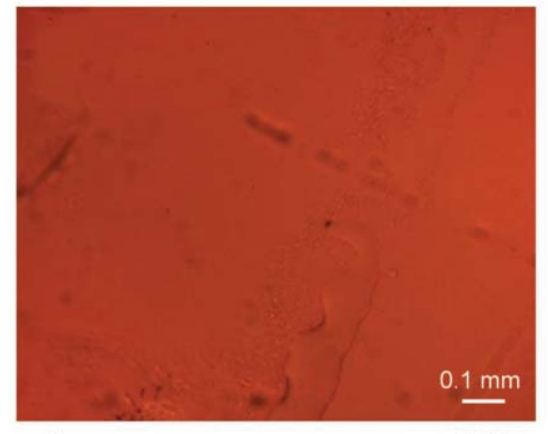

d)

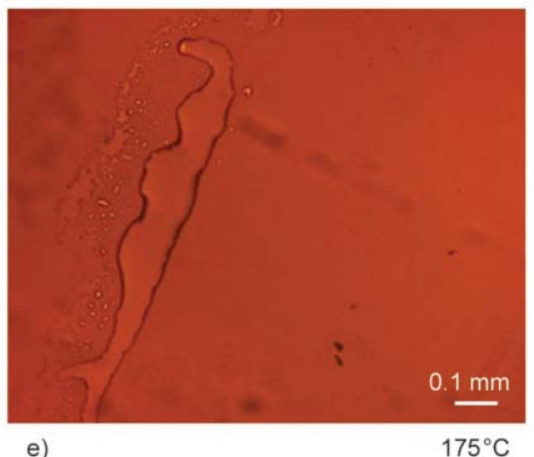

e)

Figure 3. POM micrographs of investigated systems. Sample cured at a) $155^{\circ} \mathrm{C}$, b) $160^{\circ} \mathrm{C}$, c) $165^{\circ} \mathrm{C}$, d) $170^{\circ} \mathrm{C}$, e) $175^{\circ} \mathrm{C}$. 


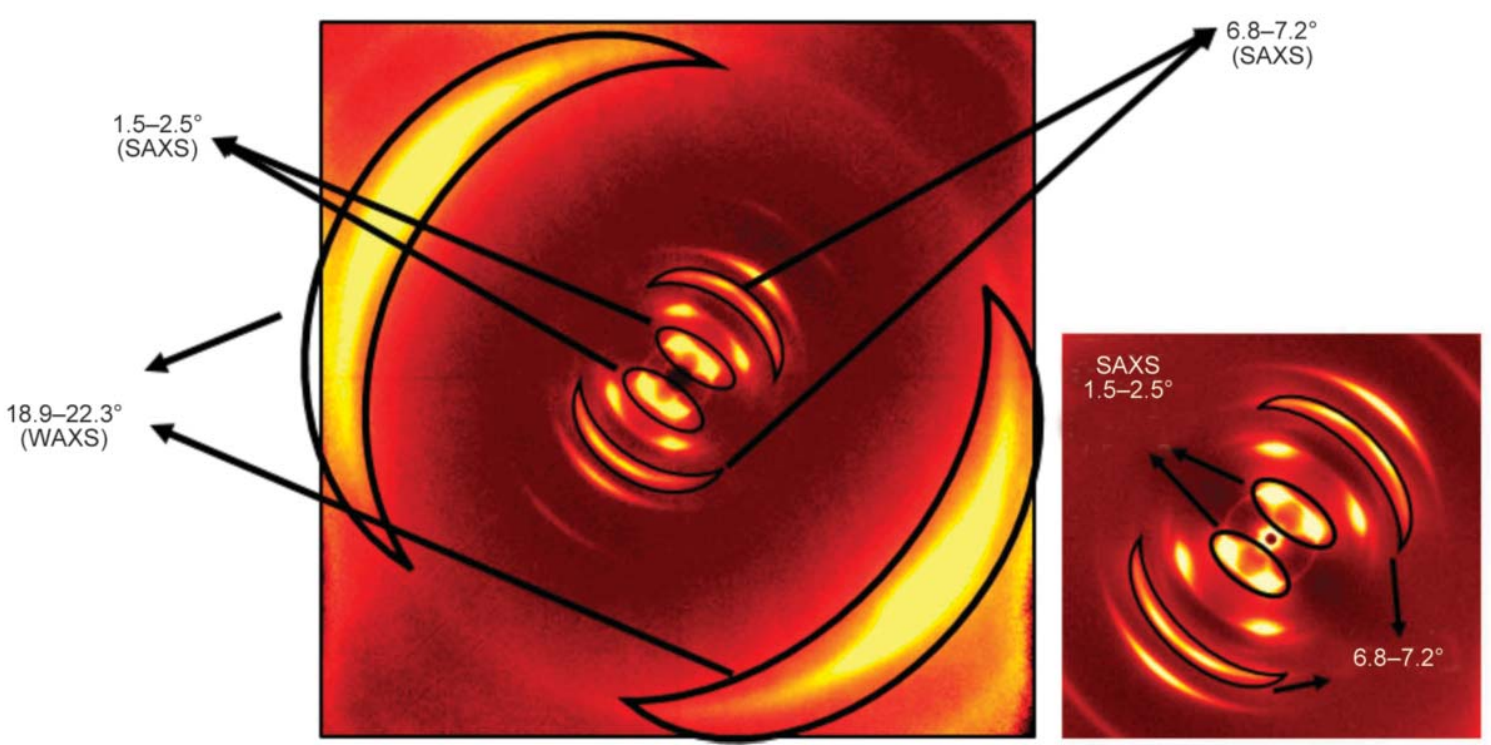

Figure 4. Scattering angles $2 \theta$ used in the calculations of the orientation function.

as every one of them was describing another structural part of the cured resin (Figure 4).

Peak intensities were found for each $2 \theta$ angle with the use of Bruker software, as shown in Figure 5. They were subsequently used to calculate the value of the orientation function described by Equation (1) presented in the Method section. For the most clearly visible interference peaks, the intensity was collected in the function of $\chi$, where the brightest spots are a representation of the most intensive radiation collected by the 2D-detector. Then, the plot of intensity is created, and based on the counts (intensity), the $O F$ can be evaluated. In this case, average maximum

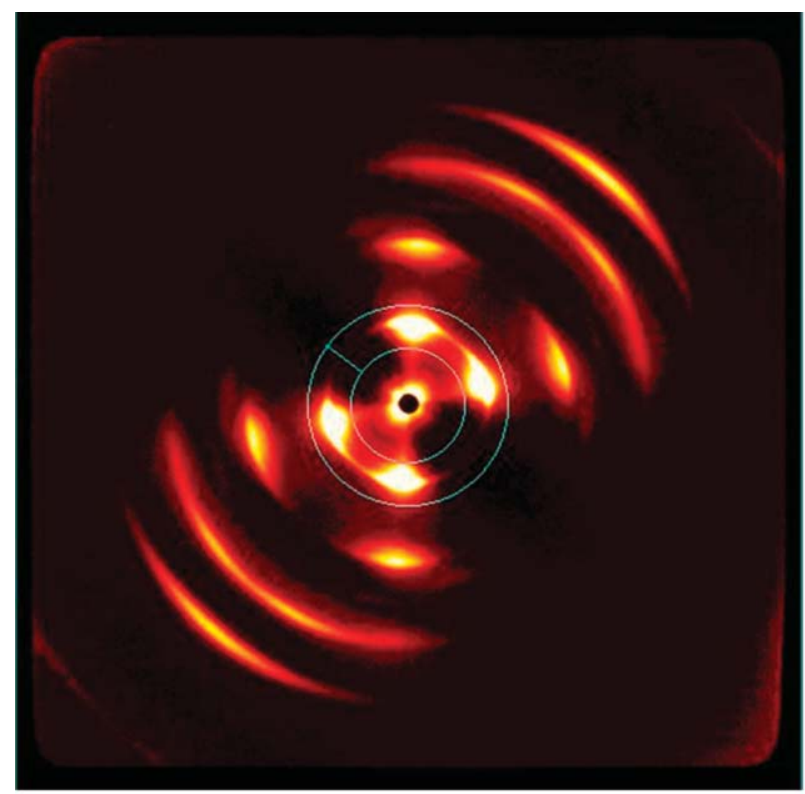

a) intensity is 71270 , minimum 1840 and FWHM 19,5, what gives $O F=0,87$,

After non-destructive X-ray scattering analysis, the DSC run was performed for each sample to determine the degree of cure. Figure 6 presents an example of such an analysis.

Presented DSC curves are a representation of the post-cure of the samples obtained in the apparatus for curing in the magnetic field. Thermogram shows that there is no curing agent in its original form (no melting of the $4,4^{\prime}-\mathrm{DDM}$ at $92^{\circ} \mathrm{C}$ ). The degree of cure was evaluated by the lack or presence of DSC peak representing LCER monomer transition into LC state

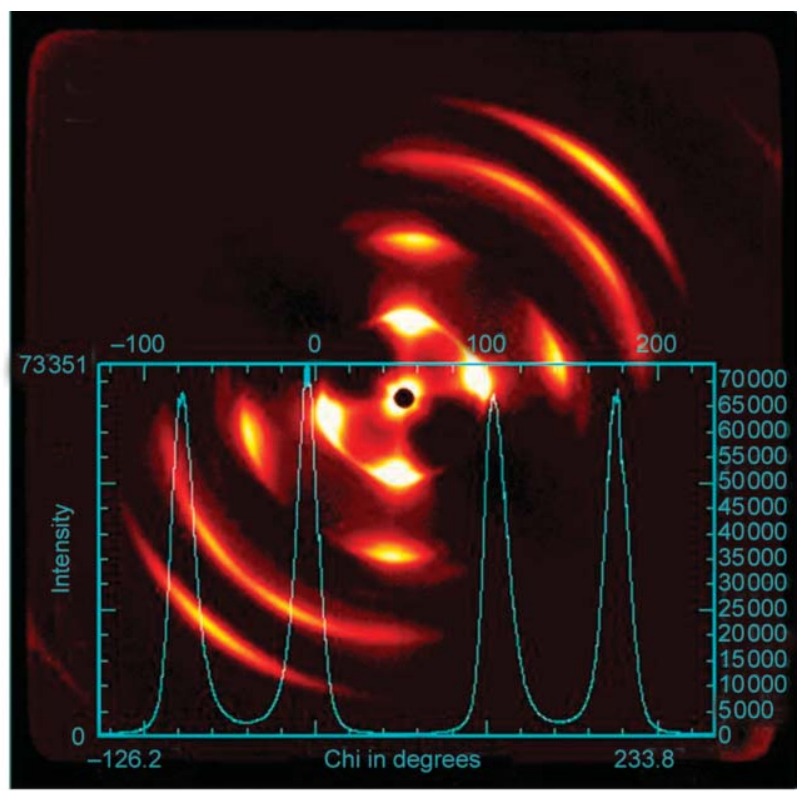

b)

Figure 5. Peak intensities collected from X-ray scattering analysis. a) One of $2 \theta$ angles $\left(\sim 2^{\circ}\right)$ chosen for analysis, b) collected scattering intensity in the form of the plot. 


$\underbrace{}_{\text {[1] 0.0 -250.0 }{ }^{\circ} \mathrm{C}, 10.00 \mathrm{~K} / \mathrm{min}}$

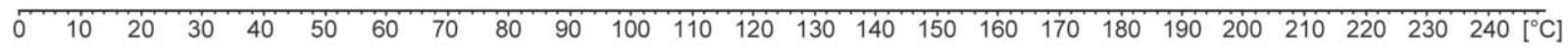

Figure 6. DSC analysis of samples prepared in the presence of the external magnetic field.

(temperature range $100-150^{\circ} \mathrm{C}$ ). As was presented in Figure 2, this transition in the 'fresh' sample has its maximum in ca. $130^{\circ} \mathrm{C}$. The fully cured system shows no such transition (see the curve of the sample cured at $175^{\circ} \mathrm{C}$ for $90 \mathrm{~min}$. This transition is solely characteristic for only partially cured samples (e.g., curing temperatures $155-170^{\circ} \mathrm{C}$ for $\left.90 \mathrm{~min}\right)$. We decided to choose this transition as diagnostic, instead of curing exothermal peak, because it is very broad in investigated systems, and residual enthalpies are so small, that this broad peak tends to be invisible on the DSC curve. The crystal-LC transition of the monomer is easier to notice and evaluate. The rise of the curve at the highest temperature shows the start of the thermal decomposition of the cured resin.

\subsection{The level of order - curing parameters dependencies - visual analysis of diffractograms}

For evaluation of the level of order, the most intuitive is the visual analysis of 2D diffractograms, as it is clearly shown, which leads to the deformation of scattering diffraction, proving an increasing anisotropy. Figures 7-9 present chosen diffractograms allowing to conclusively describe found ordering curing parameter dependencies.

Analysis of WAXS images allows determining that each curing parameter has a significant impact on the molecular anisotropy of the samples. Results indicate that the most ordered specimen can be synthesized when high magnetic induction

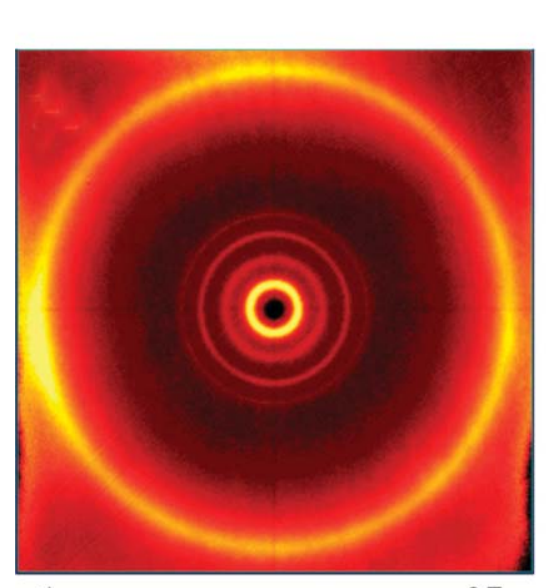

a)

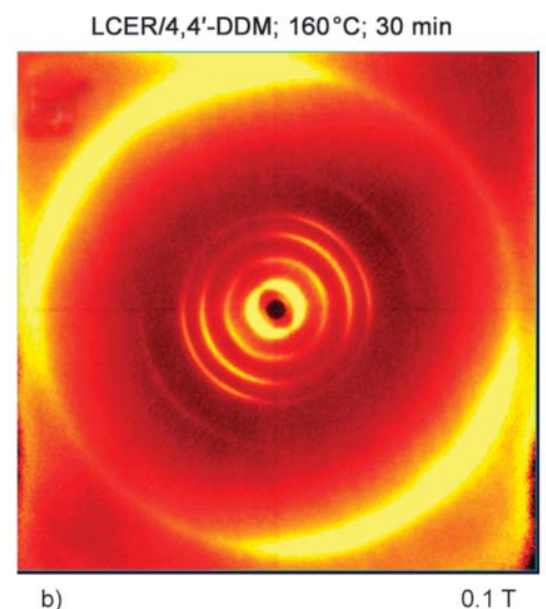

b)

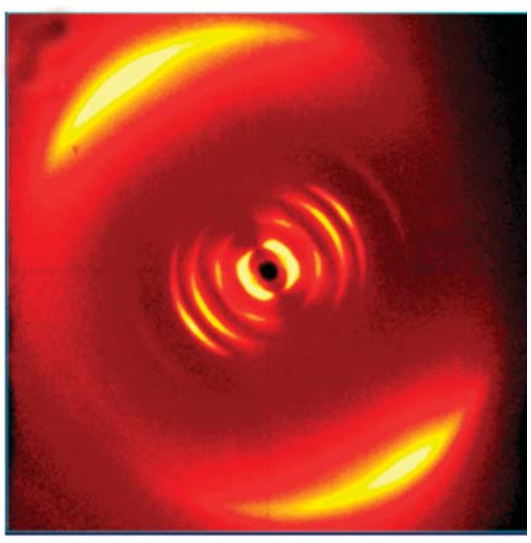

c)

$1.2 \mathrm{~T}$

Figure 7. X-ray diffractograms - the influence of magnetic induction on the level of anisotropy. a) Diffractogram of sample cured without magnetic field. b) Diffractogram of sample cured with magnetic induction of $0.1 \mathrm{~T}$. c) Diffractogram of sample cured with magnetic induction of $1.2 \mathrm{~T}$. 

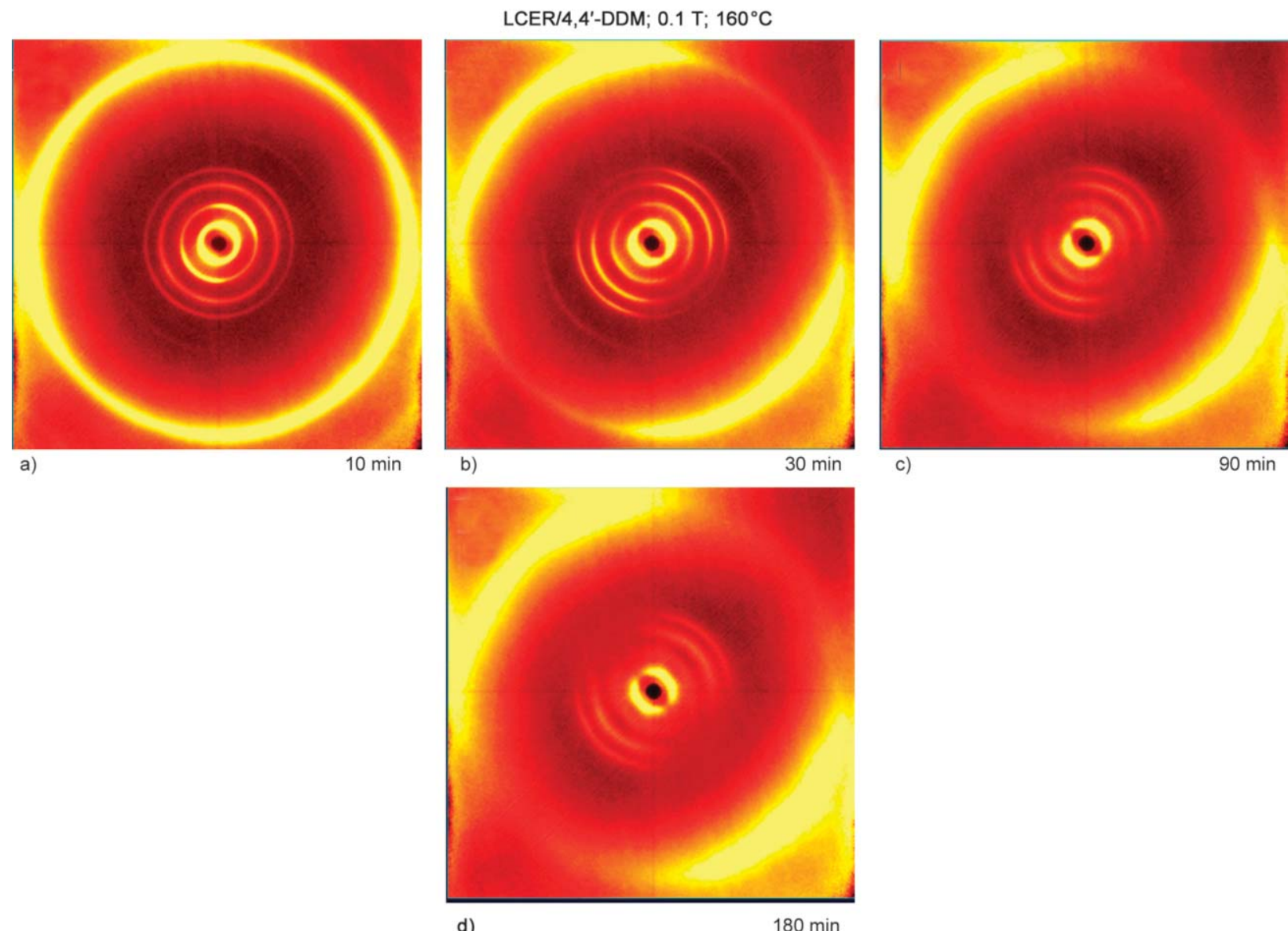

d)

$180 \mathrm{~min}$

Figure 8. X-ray diffractograms - the influence of curing time on the level of anisotropy. Diffractogram of sample cured for a) 10 minutes, b) 30 minutes, c) 90 minutes, d) 180 minutes.

is applied at lower curing temperatures. The longer time of curing can also increase the level of order.

\subsection{Evaluation of orientation function $O F$}

The complete set of results of $O F$ evaluation (Equation (1) in the Method section) is presented for all

Table 1. OF of LCER/4,4'-DDM system cured in the magnetic induction of $1.2 \mathrm{~T}$.

\begin{tabular}{|c|c|c|c|c|c|c|c|c|c|c|c|c|}
\hline \multirow{3}{*}{ Temperature } & \multicolumn{12}{|c|}{ Curing time/scattering angle, $2 \theta$} \\
\hline & \multicolumn{3}{|c|}{$10 \mathrm{~min}$} & \multicolumn{3}{|c|}{$30 \mathrm{~min}$} & \multicolumn{3}{|c|}{$90 \mathrm{~min}$} & \multicolumn{3}{|c|}{$180 \mathrm{~min}$} \\
\hline & $\sim 2^{\circ}$ & $\sim 7^{\circ}$ & $\sim 21^{\circ}$ & $\sim 2^{\circ}$ & $\sim 7^{\circ}$ & $\sim 21^{\circ}$ & $\sim 2^{\circ}$ & $\sim 7^{\circ}$ & $\sim 21^{\circ}$ & $\sim 2^{\circ}$ & $\sim 7^{\circ}$ & $\sim 21^{\circ}$ \\
\hline $155^{\circ} \mathrm{C}$ & 0.77 & 0.60 & 0.67 & 0.86 & 0.74 & 0.89 & 0.94 & 0.73 & 0.89 & 0.87 & 0.66 & 0.84 \\
\hline $160^{\circ} \mathrm{C}$ & 0.87 & 0.61 & 0.54 & 0.70 & 0.66 & 0.75 & 0.95 & 0.62 & 0.75 & 0.88 & 0.62 & 0.79 \\
\hline $165^{\circ} \mathrm{C}$ & 0.90 & 0.67 & 0.84 & 0.63 & 0.60 & 0.50 & 0.75 & 0.44 & 0.68 & 0.65 & 0.46 & 0.57 \\
\hline $170^{\circ} \mathrm{C}$ & 0.93 & 0.75 & 0.79 & 0.54 & 0.60 & 0.70 & 0.68 & 0.32 & 0.53 & 0.24 & 0.28 & 0.50 \\
\hline $175^{\circ} \mathrm{C}$ & 0.79 & 0.61 & 0.69 & 0.94 & 0.32 & 0.76 & 0.61 & 0.32 & 0.52 & 0.35 & 0.21 & 0.55 \\
\hline
\end{tabular}

Table 2. $O F$ of LCER/4,4'-DDM system cured in the magnetic induction of $0.1 \mathrm{~T}$.

\begin{tabular}{|c|c|c|c|c|c|c|c|c|c|c|c|c|}
\hline \multirow{3}{*}{ Temperature } & \multicolumn{12}{|c|}{ Curing time/scattering angle, $2 \theta$} \\
\hline & \multicolumn{3}{|c|}{$10 \mathrm{~min}$} & \multicolumn{3}{|c|}{$30 \mathrm{~min}$} & \multicolumn{3}{|c|}{$90 \mathrm{~min}$} & \multicolumn{3}{|c|}{$180 \mathrm{~min}$} \\
\hline & $\sim 2^{\circ}$ & $\sim 7^{\circ}$ & $\sim 21^{\circ}$ & $\sim 2^{\circ}$ & $\sim 7^{\circ}$ & $\sim 21^{\circ}$ & $\sim 2^{\circ}$ & $\sim 7^{\circ}$ & $\sim 21^{\circ}$ & $\sim 2^{\circ}$ & $\sim 7^{\circ}$ & $\sim 21^{\circ}$ \\
\hline $155^{\circ} \mathrm{C}$ & 0.71 & 0.62 & 0.63 & 0.63 & 0.62 & 0.44 & 0.75 & 0.50 & 0.73 & 0.77 & 0.68 & 0.75 \\
\hline $160^{\circ} \mathrm{C}$ & 0.65 & 0.55 & 0.40 & 0.62 & 0.48 & 0.32 & 0.33 & 0.30 & 0.50 & 0.69 & 0.59 & 0.51 \\
\hline $165^{\circ} \mathrm{C}$ & 0.44 & 0.35 & 0.00 & 0.48 & 0.38 & 0.00 & 0.45 & 0.38 & 0.29 & 0.51 & 0.41 & 0.37 \\
\hline $170^{\circ} \mathrm{C}$ & 0.38 & 0.21 & 0.00 & 0.39 & 0.25 & 0.00 & 0.28 & 0.24 & 0.00 & 0.24 & 0.22 & 0.33 \\
\hline $175^{\circ} \mathrm{C}$ & 0.00 & 0.00 & 0.00 & 0.15 & 0.00 & 0.00 & 0.14 & 0.00 & 0.00 & 0.11 & 0.00 & 0.00 \\
\hline
\end{tabular}




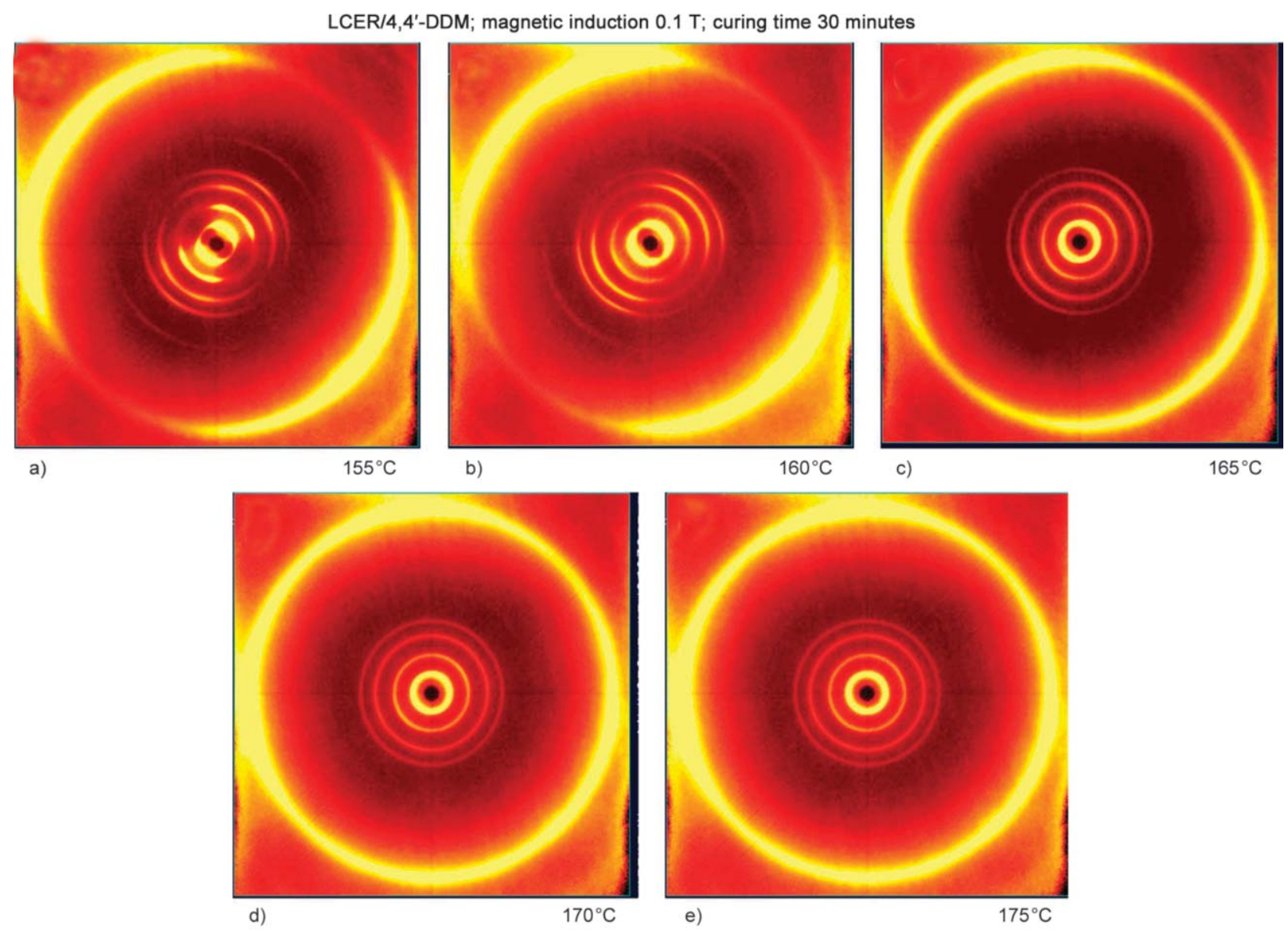

Figure 9. X-ray diffractograms - the influence of curing temperature on the level of anisotropy. Diffractogram of sample cured at a) $155^{\circ} \mathrm{C}$, b) $160^{\circ} \mathrm{C}$, c) $165^{\circ} \mathrm{C}$, d) $170^{\circ} \mathrm{C}$, e) $175^{\circ} \mathrm{C}$.

samples in the Tables $1-4 . O F=0.00$ means that no Presented Tables $1-4$ clearly show that conclusions peaks were found at scattering intensity plots. drawn form visual analysis of diffractograms are

Table 3. $O F$ of LCER/3,3'-DDM system cured in the magnetic induction of $1.2 \mathrm{~T}$.

\begin{tabular}{|c|c|c|c|c|c|c|c|c|c|c|c|c|}
\hline \multirow{3}{*}{ Temperature } & \multicolumn{12}{|c|}{ Curing time/scattering angle, $2 \theta$} \\
\hline & \multicolumn{3}{|c|}{$10 \mathrm{~min}$} & \multicolumn{3}{|c|}{$30 \mathrm{~min}$} & \multicolumn{3}{|c|}{$90 \mathrm{~min}$} & \multicolumn{3}{|c|}{$180 \mathrm{~min}$} \\
\hline & $\sim 2^{\circ}$ & $\sim 7^{\circ}$ & $\sim 21^{\circ}$ & $\sim 2^{\circ}$ & $\sim 7^{\circ}$ & $\sim 21^{\circ}$ & $\sim 2^{\circ}$ & $\sim 7^{\circ}$ & $\sim 21^{\circ}$ & $\sim 2^{\circ}$ & $\sim 7^{\circ}$ & $\sim 21^{\circ}$ \\
\hline $155^{\circ} \mathrm{C}$ & 0.87 & 0.46 & 0.71 & 0.88 & 0.63 & 0.84 & 0.88 & 0.56 & 0.84 & 0.91 & 0.53 & 0.85 \\
\hline $160^{\circ} \mathrm{C}$ & 0.89 & 0.46 & 0.70 & 0.91 & 0.62 & 0.81 & 0.51 & 0.32 & 0.43 & 0.75 & 0.53 & 0.59 \\
\hline $165^{\circ} \mathrm{C}$ & 0.83 & 0.44 & 0.44 & 0.78 & 0.57 & 0.53 & 0.33 & 0.40 & 0.47 & 0.55 & 0.47 & 0.55 \\
\hline $170^{\circ} \mathrm{C}$ & 0.10 & 0.00 & 0.52 & 0.77 & 0.57 & 0.50 & 0.34 & 0.29 & 0.44 & 0.35 & 0.25 & 0.42 \\
\hline $175^{\circ} \mathrm{C}$ & 0.11 & 0.00 & 0.56 & 0.64 & 0.22 & 0.48 & 0.41 & 0.21 & 0.31 & 0.34 & 0.21 & 0.38 \\
\hline
\end{tabular}

Table 4. $O F$ of LCER/3,3'-DDM system cured in the magnetic induction of $0.1 \mathrm{~T}$.

\begin{tabular}{|c|c|c|c|c|c|c|c|c|c|c|c|c|}
\hline \multirow{3}{*}{ Temperature } & \multicolumn{12}{|c|}{ Curing time/scattering angle, $2 \theta$} \\
\hline & \multicolumn{3}{|c|}{$10 \mathrm{~min}$} & \multicolumn{3}{|c|}{$30 \mathrm{~min}$} & \multicolumn{3}{|c|}{$90 \mathrm{~min}$} & \multicolumn{3}{|c|}{$180 \mathrm{~min}$} \\
\hline & $\sim 2^{\circ}$ & $\sim 7^{\circ}$ & $\sim 21^{\circ}$ & $\sim 2^{\circ}$ & $\sim 7^{\circ}$ & $\sim 21^{\circ}$ & $\sim 2^{\circ}$ & $\sim 7^{\circ}$ & $\sim 21^{\circ}$ & $\sim 2^{\circ}$ & $\sim 7^{\circ}$ & $\sim 21^{\circ}$ \\
\hline $155^{\circ} \mathrm{C}$ & 0.67 & 0.27 & 0.60 & 0.73 & 0.46 & 0.76 & 0.44 & 0.28 & 0.53 & 0.39 & 0.32 & 0.64 \\
\hline $160^{\circ} \mathrm{C}$ & 0.64 & 0.28 & 0.61 & 0.25 & 0.36 & 0.47 & 0.23 & 0.25 & 0.61 & 0.24 & 0.26 & 0.59 \\
\hline $165^{\circ} \mathrm{C}$ & 0.38 & 0.31 & 0.58 & 0.23 & 0.17 & 0.57 & 0.18 & 0.22 & 0.60 & 0.16 & 0.24 & 0.59 \\
\hline $170^{\circ} \mathrm{C}$ & 0.15 & 0.19 & 0.58 & 0.27 & 0.22 & 0.59 & 0.10 & 0.17 & 0.55 & 0.13 & 0.23 & 0.55 \\
\hline $175^{\circ} \mathrm{C}$ & 0.28 & 0.15 & 0.54 & 0.09 & 0.16 & 0.57 & 0.00 & 0.09 & 0.53 & 0.00 & 0.00 & 0.52 \\
\hline
\end{tabular}


sound. Values of orientation function confirm that high ordering is achieved in lower curing temperature and high magnetic induction. What is exceptionally interesting, the curing time has less impact on molecular anisotropy with the notion, that it can even deteriorate this anisotropy in some rare cases. Moreover, the differences between the two curing agents are somewhat visible, and it may be attributed to two general aspects. First of all, different isomer may present some steric hindrance, which is the most intuitive reason. But there are also proven connections between hydrogen bonding and properties of obtained epoxy samples [26], so the different isomers of DDM probably can also express in the morphological properties in that way. The formation of possible to order LC phase is feasible only in mild reaction condition, what was proven in studies of the Li and Kessler [27]. In their work, the liquid crystalline phase was developed only with low heating rates. It means that curing must proceed slowly to generate material susceptible to a magnetic field. In our case, it would be low curing temperatures, where reaction undergoes slowly. High curing temperature prevents the LC to form and thus favors isotropic polymer network.

\subsection{Evaluation of the degree of cure}

Thermosetting materials achieve full functionality in their fully cured state; it is important that besides the high level of order, the maximum possible conversion should be provided. Especially when, as described in the previous section, a short time of curing is sufficient to achieve a high value of $O F$. The results are presented below in Tables 5-8. Estimation of epoxy group conversion is based on enthalpy of transition into LC state of the unreacted monomer (details in the description of Figure 5). Lack of this transition is the evidence of maximum possible conversion.

It is worth stating that we found no influence of X-ray analyses conducted prior to DSC. Test samples were broken in half; one part was investigated by DSC before subjecting to radiation and the other part after. The results were nearly identical.

The values of diagnostic enthalpy are higher at lower temperatures, and when curing is conducted shorter. This conclusion eliminates the possibility of synthesis fully functional, highly anisotropic material in the parameters chosen as optimal by determination of orientation function. Moreover, the maximum conversion is possible only when curing temperature is
Table 5. Enthalpy of diagnostic transition, LCER/4,4'-DDM system, magnetic induction of $1.2 \mathrm{~T}$.

\begin{tabular}{|c|c|c|c|c|c|}
\hline \multicolumn{6}{|c|}{ Enthalpy of diagnostic transition, $\mathbf{\Delta H}$} \\
{$[\mathbf{J} / \mathbf{g}]$} \\
\hline \multirow{2}{*}{$\begin{array}{c}\text { Curing } \\
\text { time }\end{array}$} & \multicolumn{5}{|c|}{ Curing temperature } \\
\cline { 2 - 6 } & $\mathbf{1 6 5}^{\circ} \mathbf{C}$ & $\mathbf{1 6 0}^{\circ} \mathbf{C}$ & $\mathbf{1 6 5}^{\circ} \mathbf{C}$ & $\mathbf{1 7 0}^{\circ} \mathbf{C}$ & $\mathbf{1 7 5}^{\circ} \mathbf{C}$ \\
\hline $10 \mathrm{~min}$ & 28.94 & 24.77 & 22.46 & 21.15 & 20.00 \\
\hline $30 \mathrm{~min}$ & 17.87 & 16.68 & 15.04 & 11.74 & 11.92 \\
\hline $90 \mathrm{~min}$ & 13.60 & 7.69 & 7.68 & 8.71 & - \\
\hline $180 \mathrm{~min}$ & 8.91 & 7.46 & 6.88 & - & - \\
\hline
\end{tabular}

Table 6. Enthalpy of diagnostic transition, LCER/4,4'-DDM system, magnetic induction of $0.1 \mathrm{~T}$.

\begin{tabular}{|c|c|c|c|c|c|}
\hline \multicolumn{7}{|c|}{$\begin{array}{c}\text { Enthalpy of diagnostic transition, } \mathbf{\Delta H} \\
{[\mathbf{J} / \mathbf{g}]}\end{array}$} \\
\hline \multirow{2}{*}{$\begin{array}{c}\text { Curing } \\
\text { time }\end{array}$} & \multicolumn{5}{|c|}{$\mathbf{C u r i n g}$ temperature } \\
\cline { 2 - 6 } & $\mathbf{1 6 5}^{\circ} \mathbf{C}$ & $\mathbf{1 6 0}^{\circ} \mathbf{C}$ & $\mathbf{1 6 5}^{\circ} \mathbf{C}$ & $\mathbf{1 7 0}^{\circ} \mathbf{C}$ & $\mathbf{1 7 5}^{\circ} \mathbf{C}$ \\
\hline $10 \mathrm{~min}$ & 30.51 & 31.71 & 19.26 & 15.53 & 14.86 \\
\hline $30 \mathrm{~min}$ & 16.75 & 14.06 & 12.93 & 10.69 & 8.29 \\
\hline $90 \mathrm{~min}$ & 8.32 & 7.21 & 4.46 & - & - \\
\hline $180 \mathrm{~min}$ & 5.20 & 4.18 & - & - & - \\
\hline
\end{tabular}

Table 7. Enthalpy of diagnostic transition, LCER/3,3'-DDM system, magnetic induction of $1.2 \mathrm{~T}$.

\begin{tabular}{|c|c|c|c|c|c|}
\hline \multicolumn{6}{|c|}{ Enthalpy of diagnostic transition, $\boldsymbol{\Delta H}$} \\
{$[\mathbf{J} / \mathbf{g}]$} \\
\hline \multirow{2}{*}{$\begin{array}{c}\text { Curing } \\
\text { time }\end{array}$} & \multicolumn{5}{|c|}{ Curing temperature } \\
\cline { 2 - 6 } & $\mathbf{1 6 5}^{\circ} \mathbf{C}$ & $\mathbf{1 6 0}^{\circ} \mathbf{C}$ & $\mathbf{1 6 5}^{\circ} \mathbf{C}$ & $\mathbf{1 7 0}^{\circ} \mathbf{C}$ & $\mathbf{1 7 5}^{\circ} \mathbf{C}$ \\
\hline $10 \mathrm{~min}$ & 38.59 & 34.09 & 27.38 & 26.09 & 25.36 \\
\hline $30 \mathrm{~min}$ & 26.03 & 24.97 & 24.25 & 21.98 & 19.08 \\
\hline $90 \mathrm{~min}$ & 12.11 & 11.1 & 2.06 & - & - \\
\hline $180 \mathrm{~min}$ & 8.89 & 7.41 & - & - & - \\
\hline
\end{tabular}

Table 8. Enthalpy of diagnostic transition, LCER/3,3'-DDM system, magnetic induction of $0.1 \mathrm{~T}$.

\begin{tabular}{|c|c|c|c|c|c|}
\hline \multicolumn{6}{|c|}{ Enthalpy of diagnostic transition, $\mathbf{\Delta H}$} \\
{$[\mathbf{J} / \mathbf{g}]$} \\
\hline \multirow{2}{*}{$\begin{array}{c}\text { Curing } \\
\text { time }\end{array}$} & \multicolumn{5}{|c|}{ Curing temperature } \\
\cline { 2 - 6 } & $\mathbf{1 6 5}^{\circ} \mathbf{C}$ & $\mathbf{1 6 0}^{\circ} \mathbf{C}$ & $\mathbf{1 6 5}^{\circ} \mathbf{C}$ & $\mathbf{1 7 0}^{\circ} \mathbf{C}$ & $\mathbf{1 7 5}^{\circ} \mathbf{C}$ \\
\hline $10 \mathrm{~min}$ & 31.57 & 23.28 & 22.74 & 20.45 & 19.46 \\
\hline $30 \mathrm{~min}$ & 22.79 & 20.63 & 16.55 & 16.74 & 16.13 \\
\hline $90 \mathrm{~min}$ & 9.16 & 6.04 & 5.23 & 4.50 & 3.51 \\
\hline $180 \mathrm{~min}$ & 2.95 & 2.61 & 2.00 & 2.04 & 0.82 \\
\hline
\end{tabular}

high, what on the other hand, rules out achieving high anisotropy.

The solution lies in the two-step temperature curing with the beginning at $155^{\circ} \mathrm{C}$ for 3 hours and the increase to $175^{\circ} \mathrm{C}$ for 2 hours. The validity of this approach is proven by the lack of transition of monomer 
Table 9. $O F$ of systems cured in two-step conditions.

\begin{tabular}{|c|c|c|c|c|c|c|c|c|c|c|c|c|}
\hline \multirow{3}{*}{$\begin{array}{c}\text { Magnetic } \\
\text { induction, } \\
B\end{array}$} & \multicolumn{12}{|c|}{ Investigated system/scattering angle, $2 \theta$} \\
\hline & \multicolumn{3}{|c|}{ LCER/4,4'-DDM } & \multicolumn{3}{|c|}{ LCER/4,4'-DDM/SV2000 } & \multicolumn{3}{|c|}{ LCER/3,3'-DDM } & \multicolumn{3}{|c|}{ LCER/3,3'-DDM/SV2000 } \\
\hline & $\sim 2^{\circ}$ & $\sim 7^{\circ}$ & $\sim 21^{\circ}$ & $\sim 2^{\circ}$ & $\sim 7^{\circ}$ & $\sim 21^{\circ}$ & $\sim 2^{\circ}$ & $\sim 7^{\circ}$ & $\sim 21^{\circ}$ & $\sim 2^{\circ}$ & $\sim 7^{\circ}$ & $\sim 21^{\circ}$ \\
\hline $1.2 \mathrm{~T}$ & 0.93 & 0.52 & 0.86 & 0.47 & 0.35 & 0.76 & 0.81 & 0.38 & 0.81 & 0.89 & 0.55 & 0.87 \\
\hline $0.1 \mathrm{~T}$ & 0.71 & 0.41 & 0.78 & 0.42 & 0.34 & 0.61 & 0.61 & 0.35 & 0.61 & 0.55 & 0.39 & 0.65 \\
\hline $0.0 \mathrm{~T}$ & 0.00 & 0.00 & 0.00 & 0.00 & 0.00 & 0.00 & 0.00 & 0.00 & 0.00 & 0.00 & 0.00 & 0.00 \\
\hline
\end{tabular}

into LC state for all samples and $O F$ with values similar to those achieved in conditions concluded as optimal in the previous section of this manuscript (Table 9). Additionally, the graphite-like nanofiller SV2000 was added to the investigated systems to determine if it interferes with the process of synthesis ordered material.

The values of orientation function prove that proposed approach allows to create the epoxy polymer with highly ordered molecular structure and that introduction of SV2000 anthracite filler generally slightly deteriorates the level of anisotropy (with the exception of a system with 3,3'-DDM cured in a strong magnetic field - this may be caused by different steric interference with bent molecules of the curing agent). The presence of nanofiller particles probably blocks the possibility of contact of functional groups in some cases and forces it to react in the slightly less ordered geometrical configuration.

As the tables with more than 200 different results are hard to parse, we suggest that the easiest way to conclude is by analyzing Figures 7-9, which in our opinion, allow seeing the most valuable conclusions concerning optimization of the cure. However, Table 10, presenting the most valuable results as it contains $O F$ of the samples cured in optimal conditions in also represented in the form of the chart (Figure 10). It clearly shows that general conclusions are correct: two-step curing does not deteriorate the $O F$ (values over 0.8 with the induction of $1.2 \mathrm{~T}$ ) compared to one-step $155^{\circ} \mathrm{C}$ curing and the strongest magnetic field, the greater is the ordering (the blue column is always evidently the highest).

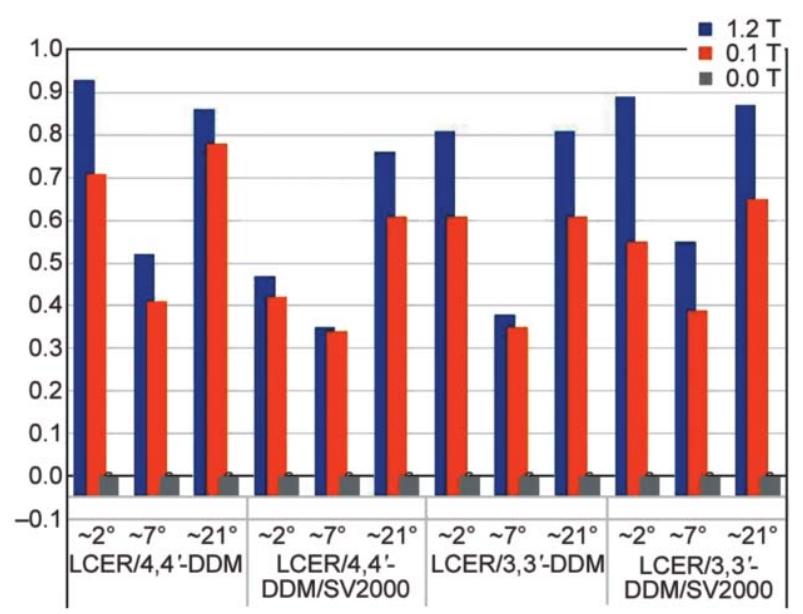

Figure 10. Chart presenting the $O F$ of the samples cured in the optimal, two-step conditions.

\subsection{Properties of synthesized anisotropic polymer networks obtained in the two- step conditions}

The samples considered as obtained in the condition favoring big anisotropy and conversion were tested in several ways. Table 10 present glass transition of those samples.

It is clearly shown that anthracite filler, despite its plate-like rigid structure, is decreasing the glass transition of the obtained samples. It is somewhat surprising; however, literature brings information that non-oxidized carbon fillers can have this effect due to insufficient dispersion in the matrix $[28,29]$ or the limitations of polymer chain movement [30] and increasing the activation energy [31]. It leads to nonhomogenous material with slightly lower epoxy conversion, which explains the results.

Table 10. Glass transition of samples cured in two-step temperature program $\left(155^{\circ} \mathrm{C}-3 \mathrm{~h} / 175^{\circ} \mathrm{C}-2 \mathrm{~h}\right)$.

\begin{tabular}{|c|c|c|c|c|}
\hline \multicolumn{5}{|c|}{$\begin{array}{c}\text { Glass transition, } \boldsymbol{T}_{\mathrm{g}} \\
{\left[{ }^{\circ} \mathbf{C}\right]}\end{array}$} \\
\hline Magnetic induction, $\boldsymbol{B}$ & LCER/4.4'-DDM & LCER/4.4' ${ }^{\prime}$-DDM/SV2000 & LCER/3.3'-DDM & LCER/3.3'-DDM/SV2000 \\
\hline $1.2 \mathrm{~T}$ & 86.5 & 78.5 & 82.9 & 76.0 \\
\hline $0.1 \mathrm{~T}$ & 84.0 & 78.2 & 72.4 & 73.2 \\
\hline $0.0 \mathrm{~T}$ & 84.5 & 75.5 & 73.2 & 71.4 \\
\hline
\end{tabular}


$12 \mathrm{~T}$

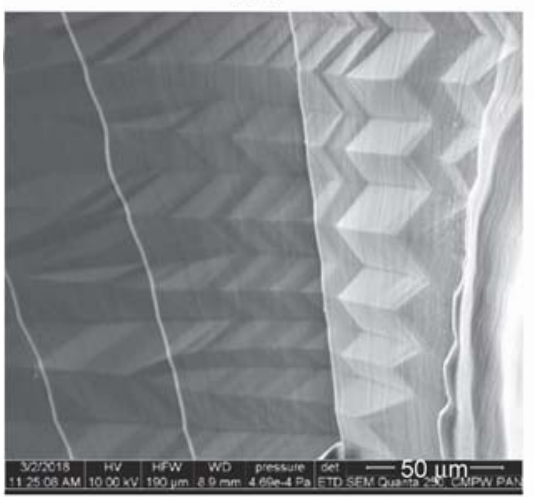

a)
$0.1 \mathrm{~T}$

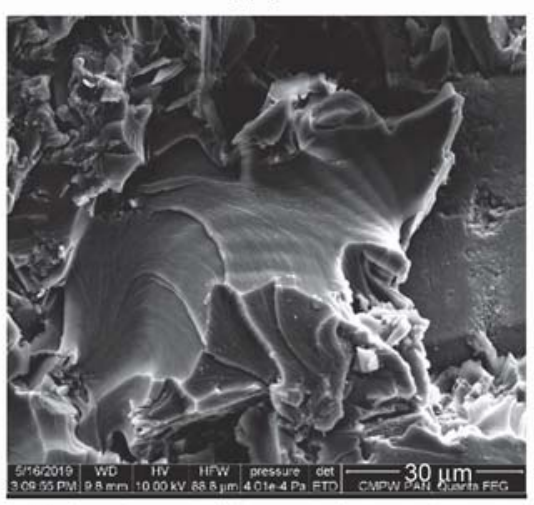

b)

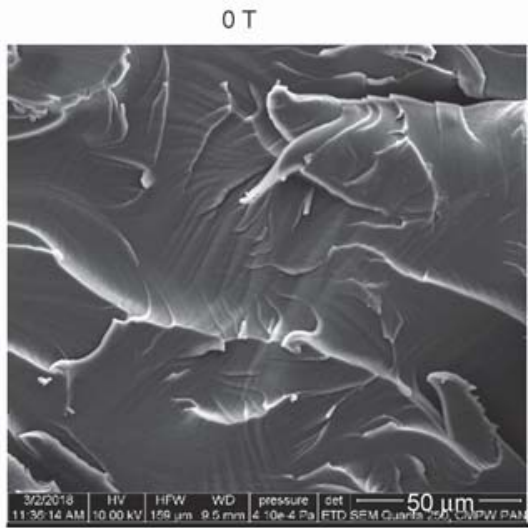

c)

Figure 11. SEM micrographs of the LCER/3.3'-DDM system cured with different magnetic induction. SEM micrograph of sample cured with magnetic induction of a) $1.2 \mathrm{~T}, \mathrm{~b}$ ) $0.1 \mathrm{~T}, \mathrm{c}$ ) SEM micrograph of sample cured without magnetic field.

Another conclusion could be the notion that anisotropy caused by high magnetic induction is increasing the glass transition temperature (especially in LCER/3.3'-DDM system) thanks to the specific orientation of molecules proven by SEM observations presented in Figure 11. The uniformly layered (smectic) structure is obtained only in the high magnetic induction, which can be the cause of the higher glass transition temperature. Other samples present locally layered structure, not oriented, however, in any specific direction. Literature provides information that structural anisotropy can indeed influence the network properties [32]. Similar findings were discovered for the system with 4,4'-DDM as a curing agent.

Also, the thermomechanical properties of synthesized samples were investigated. The results are collected in Table 11. Analyses were performed applying stress perpendicularly $(+)$ or parallelly $(\|)$ to the lines of the magnetic field during curing. $T_{\mathrm{g}}$ obtained from DSC analyses was added for clarity of comparison.

DMA analysis confirmed some results obtained from DSC curves. The addition of the filler generally decreases the $T_{\mathrm{g}}$ and reasons for that were mentioned in the 'DSC results' discussion. Despite lowering the

Table 11. Results of the DMA analyses for two-step conditions curing.

\begin{tabular}{|c|c|c|c|c|c|c|}
\hline Hardener & Filler & Induction, $B$ & $\|$ or + & $\begin{array}{c}T_{\mathrm{g}} \mathrm{DSC} \\
{\left[{ }^{\circ} \mathrm{C}\right]}\end{array}$ & $\begin{array}{c}T_{\mathrm{g}} \text { DMA } \\
{\left[{ }^{\circ} \mathrm{C}\right]}\end{array}$ & $\begin{array}{c}G^{\prime}\left(50^{\circ} \mathrm{C}\right) \\
{[\mathrm{MPa}]}\end{array}$ \\
\hline 4.4'-DDM & - & $1.2 \mathrm{~T}$ & $t$ & 86.5 & 117.0 & 585 \\
\hline 4.4'-DDM & - & $1.2 \mathrm{~T}$ & $\|$ & 86.5 & 110.0 & 545 \\
\hline 4.4'-DDM & - & $0.1 \mathrm{~T}$ & $t$ & 84.0 & 97.1 & 519 \\
\hline 4.4'-DDM & - & $0.1 \mathrm{~T}$ & $\|$ & 84.0 & 92.5 & 523 \\
\hline 4.4'-DDM & - & $0.0 \mathrm{~T}$ & & 84.5 & 94.8 & 466 \\
\hline 3.3'-DDM & - & $1.2 \mathrm{~T}$ & $t$ & 82.9 & 84.1 & 599 \\
\hline 3.3'-DDM & - & $1.2 \mathrm{~T}$ & $\|$ & 82.9 & 110.0 & 505 \\
\hline 3.3'-DDM & - & $0.1 \mathrm{~T}$ & $t$ & 72.4 & 82.3 & 498 \\
\hline 3.3'-DDM & - & $0.1 \mathrm{~T}$ & $\|$ & 72.4 & 79.6 & 627 \\
\hline 3.3'-DDM & - & $0.0 \mathrm{~T}$ & & 73.2 & 83.7 & 726 \\
\hline 4.4'-DDM & SV2000 & $1.2 \mathrm{~T}$ & $t$ & 78.5 & 102.9 & 517 \\
\hline 4.4'-DDM & SV2000 & $1.2 \mathrm{~T}$ & $\|$ & 78.5 & 81.0 & 517 \\
\hline 4.4'-DDM & SV2000 & $0.1 \mathrm{~T}$ & $t$ & 78.2 & 95.4 & 739 \\
\hline 4.4'-DDM & SV2000 & $0.1 \mathrm{~T}$ & $\|$ & 78.2 & 86.4 & 531 \\
\hline 4.4'-DDM & SV2000 & $0.0 \mathrm{~T}$ & & 75.5 & 81.7 & 510 \\
\hline 3.3'-DDM & SV2000 & $1.2 \mathrm{~T}$ & t & 76.0 & 85.7 & 649 \\
\hline 3.3'-DDM & SV2000 & $1.2 \mathrm{~T}$ & $\|$ & 76.0 & 84.1 & 757 \\
\hline 3.3'-DDM & SV2000 & $0.1 \mathrm{~T}$ & t & 73.2 & 84.7 & 980 \\
\hline 3.3'-DDM & SV2000 & $0.1 \mathrm{~T}$ & $\|$ & 73.2 & 84.7 & 1060 \\
\hline 3.3'-DDM & SV2000 & $0.0 \mathrm{~T}$ & & 71.4 & 83.7 & 733 \\
\hline
\end{tabular}


$T_{\mathrm{g}}$, the addition of the carbon filler has an increasing effect on the storage modulus in the glassy state. Other groups found similar results, and this phenomenon is probably the effect of filler particles rigidness and easier aligning the matrix chains along with them $[33,34]$. The direction of the shearing force during analysis has a rather subtle effect on the results, and this might be contributed to not uniform dispersion of the filler, what may have caused impossible to see clear tendencies. Another possible reason for that lies in the molecular structure of the network. It was described before by our team [22] that mesogenic layers are positioned at somewhat close to $45^{\circ}$ angle to the sample surface, so it is possible that stressing it perpendicularly or parallelly to this surface gives very similar conditions in average. Worth noticing is also a big difference between $T_{\mathrm{g}}$ obtained from DSC and DMA in samples synthesized with high magnetic induction. The anisotropic structure has reinforced the obtained material. Some researchers also found a similar effect calling the LC-epoxy 'self-reinforcing' [35].

\section{Conclusions}

Conditions of the curing process have a great impact on the properties of the synthesized material. Manipulation with time, temperature, and the induction of the magnetic field create a possibility of developing highly ordered polymer with potentially superior properties, like high glass transition temperature possible to achieve by so-called self-reinforcing. Results obtained in DMA analysis indicate that materials of this kind can be used as high-tech construction composites. LCER composites, in general, however, can present sophisticated properties like electrical conductivity [36], anisotropic optical properties [37], or the shape memory [38]. Investigating those possibilities is our aim in the future.

Conducted X-ray diffraction and DSC analyses allowed to determine some clear dependencies between curing conditions and structural characteristics of samples. The most anisotropic material can be prepared in high magnetic induction and a rather low curing temperature $(O F$ reaching values about 0.9 in contrast to $O F$ often smaller than 0.5 in low induction and high temperature - especially in the case of LCER/4,4'-DDM system, when $O F$ is close to 0 in average). Time of curing is less important for achieving high ordering exclusively, but it is needed for the curing to end with maximum possible conversion (diagnostic enthalpy is 3 to 10 times smaller after 3 hours curing in comparison to 10 minutes curing). When this is impossible at a lower temperature, the two-step curing program is required to obtain both the high anisotropy and conversion (maximum $O F$ also reaching 0.9 . with no residual enthalpy).

The optimal conditions for achieving anisotropic materials from investigated systems are high magnetic induction $(1.2 \mathrm{~T})$ and two-step temperature program $\left(155^{\circ} \mathrm{C}-3 \mathrm{~h} / 175^{\circ} \mathrm{C}-2 \mathrm{~h}\right)$. Those conclusions should be very interesting and useful for other researchers trying to achieve similarly ordered materials.

\section{Acknowledgements}

The authors would like to sincerely thank Mr. Piotr Szałański for his contribution to this work.

\section{References}

[1] Mohan P.: A critical review: The modification, properties, and applications of epoxy resins. Polymer-Plastics Technology and Engineering, 52, 107-125 (2013). https://doi.org/10.1080/03602559.2012.727057

[2] Srivastava A. K., Mohan P.: Synthesis, reactions, and properties of modified epoxy resins. Journal of Macromolecular Science Part C: Polymer Reviews, 37, 687716 (1997).

https://doi.org/10.1080/15321799708009653

[3] Paluvai N. R., Mohanty S., Nayak S. K.: Synthesis and modifications of epoxy resins and their composites: A review. Polymer-Plastics Technology and Engineering, 53, 1723-1758 (2014).

https://doi.org/10.1080/03602559.2014.919658

[4] Thakur T., Jaswal S., Parihar S., Gaur B., Singha A. S.: Bio-based epoxy thermosets with rosin derived imidoamine curing agents and their structure-property relationships. Express Polymer Letters, 14, 512-529 (2020). https://doi.org/10.3144/expresspolymlett.2020.42

[5] Mahmood H., Dorigato A., Pegoretti A.: Thermal mending in novel epoxy/cyclic olefin copolymer blends. Express Polymer Letters, 14, 368-383 (2020). https://doi.org/10.3144/expresspolymlett.2020.31

[6] Miranda T. B., Silva G. G.: Hierarchical microstructure of nanoparticles of calcium carbonate/epoxy composites: Thermomechanical and surface properties. Express Polymer Letters, 14, 179-191 (2020). https://doi.org/10.3144/expresspolymlett.2020.15

[7] Kularatne R. S., Kim H., Boothby J. M., Ware T. H.: Liquid crystal elastomer actuators: Synthesis, alignment, and applications. Journal of Polymer Science Part B: Polymer Physics, 55, 395-411 (2017). https://doi.org/10.1002/polb.24287

[8] Andrienko D.: Introduction to liquid crystals. Journal of Molecular Liquids, 267, 520-541 (2018). https://doi.org/10.1016/j.molliq.2018.01.175 
[9] Blinov L. M.: Structure and properties of liquid crystals. Springer, Dordrecht (2014).

[10] Kisiel M., Mossety-Leszczak B.: Development in liquid crystalline epoxy resins and composites $-\mathrm{A}$ review. European Polymer Journal, 124, 109507/1-109507/12 (2020).

https://doi.org/10.1016/j.eurpolymj.2020.109507

[11] Mossety-Leszczak B., Kisiel M., Szałański P., Włodarska M., Szeluga U., Pusz S.: The influence of a magnetic field on the morphology and thermomechanical properties of a liquid crystalline epoxy carbon composite. Polymer Composites, 39, E2573-E2583 (2018). https://doi.org/10.1002/pc.24848

[12] Włodarska M., Mossety-Leszczak B., Bąk G. W., Kisiel M., Dłużniewski M., Okrasa L.: Epoxy matrix with triaromatic mesogenic unit in dielectric spectroscopy observation. Spectrochimica Acta Part A: Molecular and Biomolecular Spectroscopy, 194, 102-110 (2018). https://doi.org/10.1016/j.saa.2018.01.001

[13] Zhang C., Bunning T. J., Laine R. M.: Synthesis and characterization of liquid crystalline silsesquioxanes. Chemistry of Materials, 13, 3653-3662 (2001). https://doi.org/10.1021/cm0100467

[14] Kuo S-W., Chang F-C.: POSS related polymer nanocomposites. Progress in Polymer Science, 36, 1649-1696 (2011).

https://doi.org/10.1016/j.progpolymsci.2011.05.002

[15] Bakir M., Meyer J. L., Pang S., Economy J., Jasiuk I.: Merging versatile polymer chemistry with multifunctional nanoparticles: An overview of crosslinkable aromatic polyester matrix nanocomposites. Soft Matter, 16, 1389-1403 (2020). https://doi.org/10.1039/c9sm02129a

[16] Yang X., Zhu J., Yang D., Zhang J., Guo Y., Zhong X., Kong J., Gu J.: High-efficiency improvement of thermal conductivities for epoxy composites from synthesized liquid crystal epoxy followed by doping BN fillers. Composites Part B: Engineering, 185, 107784/1107784/8 (2020). https://doi.org/10.1016/j.compositesb.2020.107784

[17] Fitriyani S., Liu C. Y., Hung Y. H., Zhang Y. S., Liu J. H.: Bending control of liquid-crystal elastomers based on doped azo derivatives synthesized via controlled gradient polymerization. Express Polymer Letters, 14, 566-575 (2020).

https://doi.org/10.3144/expresspolymlett.2020.46

[18] Dattler D., Fuks G., Heiser J., Moulin E., Perrot A., Yao X., Giuseppone N.: Design of collective motions from synthetic molecular switches, rotors, and motors. Chemical Reviews, 120, 310-433 (2020).

https://doi.org/10.1021/acs.chemrev.9b00288

[19] Shen W., Wang L., Zhong T., Chen G., Li C., Chen M., Zhang C., Zhang L., Li K., Yang Z., Yang H.: Electrically switchable light transmittance of epoxy-mercaptan polymer/nematic liquid crystal composites with controllable microstructures. Polymer, 160, 53-64 (2019). https://doi.org/10.1016/j.polymer.2018.11.022
[20] Kakiuchida H., Ogiwara A.: Reverse-mode thermoresponsive light attenuators produced by optical anisotropic composites of nematic liquid crystals and reactive mesogens. Optical Materials, 78, 273-278 (2018). https://doi.org/10.1016/j.optmat.2018.01.046

[21] Chow W. S., Mohd Ishak Z. A.: Smart polymer nanocomposites: A review. Express Polymer Letters, 14, 416435 (2020).

https://doi.org/10.3144/expresspolymlett.2020.35

[22] Mossety-Leszczak B., Strachota B., Strachota A., Steinhart M., Šlouf M.: The orientation-enhancing effect of diphenyl aluminium phosphate nanorods in a liquid-crystalline epoxy matrix ordered by magnetic field. European Polymer Journal, 72, 238-255 (2015). https://doi.org/10.1016/j.eurpolymj.2015.09.018

[23] Galina H., Mossety-Leszczak B.: Liquid-crystalline epoxy resins. Journal of Applied Polymer Science, 105, 224-228 (2007).

https://doi.org/10.1002/app.26014

[24] Pusz S., Szeluga U., Nagel B., Czajkowska S., Galina H., Strzezik J.: The influence of structural order of anthracite fillers on the curing behavior, morphology, and dynamic mechanical thermal properties of epoxy composites. Polymer Composites, 36, 336-347 (2015). https://doi.org/10.1002/pc.22948

[25] Mossety-Leszczak B., Kisiel M., Lechowicz J. B., Buszta N., Ostatek R., Włodarska M.: Analysis of curing reaction of liquid-crystalline epoxy compositions by using temperature-modulated DSC TOPEM ${ }^{\circledR}$. Journal of Thermal Analysis and Calorimetry, 138, 24352444 (2019).

https://doi.org/10.1007/s10973-019-08193-w

[26] Meng F., Zheng S., Liu T.: Epoxy resin containing poly(ethylene oxide)-block-poly( $\varepsilon$-caprolactone) diblock copolymer: Effect of curing agents on nanostructures. Polymer, 47, 7590-7600 (2006).

https://doi.org/10.1016/j.polymer.2006.08.050

[27] Li Y., Kessler M. R.: Cure kinetics of liquid crystalline epoxy resins based on biphenyl mesogen. Journal of Thermal Analysis and Calorimetry, 117, 481-488 (2014). https://doi.org/10.1007/s10973-014-3647-0

[28] Liang J., Sun J., Zhao Q., Lin Y., Zhou Q.: The curing behavior and properties of diglycidyl ether of 4,4'-bis(4hydroxybenzoyloxy)-3,3',5,5'-tetramethylbiphenyl and its composites with multi-wall carbon nanotubes. Polymer-Plastics Technology and Engineering, 49, 14281432 (2010). https://doi.org/10.1080/03602559.2010.496404

[29] Sahoo N. G., Rana S., Cho J. W., Li L., Chan S. H.: Polymer nanocomposites based on functionalized carbon nanotubes. Progress in Polymer Science, 35, 837867 (2010). https://doi.org/10.1016/j.progpolymsci.2010.03.002 
[30] Chen S., Hsu S-H., Wu M-C., Su W. F.: Kinetics studies on the accelerated curing of liquid crystalline epoxy resin/multiwalled carbon nanotube nanocomposites. Journal of Polymer Science Part B: Polymer Physics, 49, 301-309 (2011).

https://doi.org/10.1002/polb.22179

[31] Bae J., Jang J., Yoon S-H.: Cure behavior of the liquidcrystalline epoxy/carbon nanotube system and the effect of surface treatment of carbon fillers on cure reaction. Macromolecular Chemistry and Physics, 203, 2196-2204 (2002).

https://doi.org/10.1002/15213935(200211)203:15<2196::AID-MACP2196>3.0.CO;2-U

[32] Harada M., Ochi M., Tobita M., Kimura T., Ishigaki T., Shimoyama N., Aoki H.: Thermomechanical properties of liquid-crystalline epoxy networks arranged by a magnetic field. Journal of Polymer Science Part B: Polymer Physics, 42, 758-765 (2004).

https://doi.org/10.1002/polb.10740

[33] Hsu S-H., Wu M-C., Chen S., Chuang C-M., Lin S-H., $\mathrm{Su}$ W-F.: Synthesis, morphology and physical properties of multi-walled carbon nanotube/biphenyl liquid crystalline epoxy composites. Carbon, 50, 896-905 (2012).

https://doi.org/10.1016/j.carbon.2011.09.051
[34] Qi B., Yuan Z., Lu S., Liu K., Li S., Yang L., Yu J.: Mechanical and thermal properties of epoxy composites containing graphene oxide and liquid crystalline epoxy. Fibers and Polymers, 15, 326-333 (2014). https://doi.org/10.1007/S12221-014-0326-5

[35] Li Y., Kessler M. R.: Creep-resistant behavior of selfreinforcing liquid crystalline epoxy resins. Polymer, 55, 2021-2027 (2014). https://doi.org/10.1016/j.polymer.2014.03.001

[36] Shen W., Cao Y., Zhang C., Yuan X., Yang Z., Zhang L.: Network morphology and electro-optical characterisations of epoxy-based polymer stabilised liquid crystals. Liquid Crystals, 47, 481-488 (2020). https://doi.org/10.1080/02678292.2019.1658814

[37] Carfagna C., Amendola E., Giamberini M.: Liquid crystalline epoxy based thermosetting polymers. Progress in Polymer Science, 22, 1607-1647 (1997). https://doi.org/10.1016/S0079-6700(97)00010-5

[38] Lama G. C., Cerruti P., Lavorgna M., Carfagna C., Ambrogi V., Gentile G.: Controlled actuation of a carbon nanotube/epoxy shape-memory liquid crystalline elastomer. Journal of Physical Chemistry C, 120, $24417-$ 24426 (2016). https://doi.org/10.1021/acs.jpcc.6b06550 